Borneo Journal of Sciences \& Technology, Volume (3), Issue (1), Pages: 66-76

DOI: http://doi.org/10.3570/bjost.2021.3.1-10

e-ISSN: 2672-7439

(C) 2018, UCTS Publisher.

Submitted: $20^{\text {th }}$ October $2020 \quad$ Accepted: $13^{\text {th }}$ December $2020 \quad$ Published: $31^{\text {st }}$ January 2021

\title{
Characterization of Oil Palm Fronds Panel at Different Conditions and Positions with Formaldehyde Adhesive
}

\author{
${ }^{1,4}$ Razak Wahab, ${ }^{2}$ Mohd Sukhairi Mat Rasat, ${ }^{1,4}$ Mohamad Saiful Sulaiman, ${ }^{3}$ Muhammad Haziq Razak, \\ ${ }^{1,4}$ Nasihah Mokhtar and ${ }^{1,4}$ Taharah Edin \\ ${ }^{1}$ University College of Technology Sarawak (UCTS), 96000 Sibu, Sarawak \\ ${ }^{2}$ Universiti Malaysia Kelantan (UMK), 17000 Jeli, Kelantan \\ ${ }^{3}$ Universiti Sains Malaysia (USM), 11800 Penang \\ ${ }^{4}$ Centre of Excellence in Wood Engineered Product, UCTS, 96000 Sibu, Sarawak
}

\begin{abstract}
This experimental study investigated the fabrications of bio-composite, namely as a panels fronds oil palm (PFOP). The Phenol-formaldehyde (PF) and urea-formaldehyde (UF) adhesives used as the coupling agent for binding the fibres together. The frond samples segregated into three conditions which are dried fronds, felled fronds and green fronds. Each frond subdivided into the three positions which are bottom, middle and top. To avoid an incomplete mixture, all unwanted part such as the leaflets and the epidermis removed from the fronds. The samples sliced longitudinally into long thin fibres then compressed into a size of $2-3 \mathrm{~mm}$ thickness using a $350 \mathrm{~mm} \times 350 \mathrm{~mm}$ x $20 \mathrm{~mm}$ mould. Dried compressed layers were mixed with PF and UF at $12-15 \%$, respectively. $1 \%$ ammonium chloride $(\mathrm{NH} 4 \mathrm{Cl})$ added as a hardener for composite. A single compressed layer combined with a few layers to forming panel boards. To measure the effectiveness of PFOP, the physical and strength properties was carried out as followed the ISO standards. Results found that the bio-composite PFOP produced possessed properties to be equivalent to the rubberwood properties. The statistical analysis highlighted there are significant differences between PFOP made from each parameter. The modification observed no significant differences in the adhesives types. Fabrication of bio-composite PFOP has considerable potential as an alternative for wood to overcome the shortage of materials in the wood industry.
\end{abstract}

Keywords: Panels fronds oil palm (PFOP), Oil palm bio-composite, Physical properties, Strength properties, Formaldehyde

\section{INTRODUCTION}

Agricultural biomass is the most abundant bioresources and most renewable. Oil palm stems and fronds produced in abundant has become a significant environmental issue to the plantation owners [1],[2]. These agriculture wastes were is the most abundant usually left to rot in the fields. After a specific period, these materials naturally turned into natural fertilizer. The piles of these materials can attract rats, snakes, and other small size animals to makes nests, and creates safety problems to workers collecting oil palm fruits. Turning these bio-materials resource into useful products could solve this problem. Only $10 \%$ of the oil palm biomass is used as an alternative raw material for various application [3],[4].

Currently, research has focussed on the utilization of the oil palm stems as an alternative material to wood. This bio-resource material has the potential to be used as veneers in the plywood, boards, panels, and particle boards manufacturing. On the other hand, the oil palm fronds which are available the whole year round left untouched after they fell from the trees. The increase in wood prices and shortage in supply of accessible wood species timber has affected the wood-based industries [5]. This cause the increase in the manufacturing costs and the concerned in climate change due to rapid depletion in the natural forest. The forest could no longer supply the woods in a vast quantity. Research and development activities are intensively taking place searching on bio-composites non-wood resources [1]. Agriculture sector with an abundant supply of waste residues has been looked as the alternative source for raw material [6]. Non-wood lignocelluloses composites are becoming attractive in both commercial and noncommercial applications.

Organic natural fibres increasingly investigated for various usages in many structural and non-structural

Corresponding Author: Razak Wahab. Centre of Excellence in Wood Engineered Product (UCTS),

Email: drrazakw5181@ucts.edu.my 
applications. Malaysia produced a vast quantity of agricultural waste such as coir fibre, rice husk and oil palm fibre [7]. These materials are renewable, nonabrasive, cheaper, abundance and show less health and safety concern during handling and processing. The uses of agriculture residues combined with other lignocelluloses material, metals, plastics, glass and synthetic fibres could reduce the dependent of bioresources from the natural forests [8].

Oil palm fronds can be a solution as they are obtainable all the year-round. These bioresources appear to be the most viable alternative utilized as the value-added product alternative to timber [9]. A vast quantity of oil palm biomass which includes the tree trunk, fronds, empty fruit bunch, shell, and fibre available especially during replanting season. Efforts were currently undertaken to utilize empty fruit bunches contemplated mainly on the production of pulp for papermaking [10],[11], medium density fibreboard [12],[13], oil palm fibre mattress and agricultural mats, high-quality organic fertilizer, charcoal briquette and roof tiles [10]. The production of medium density fibreboard [14], cement-bonded particleboard [15], fibre reinforced cement board [16],[17\}, fibre plastic composite [18] and plywood [19],[20] from oil palm trunk beside laminated veneer panels [21]. Research focusing on the potential uses of oil palm fronds as a future alternative to woods are lacking. This study investigated possible benefits of oil palm fronds as quality materials in the wood-based industry based on their physical and strength properties.

\section{MATERIALS AND METHODS}

\section{Preparation bio composite PFOP}

The fronds of the oil palm trees used in this study were obtained from a private plantation in Sibu, Sarawak. Only fronds from decay-free trees and with no obvious defect were selected. The selected fronds were divided into three (3) condition groups of dried, felled, and green fronds. They were further sub-divided into three portions, namely the bottom, middle and top. The leaflets removed from the selected fronds.

Nonetheless, discs about $10 \mathrm{~cm}$ in the middle were cut from every portion for the physical properties study for the fresh oil palm frond and the rest were peeled of their skin and sliced in the longitudinal direction. The fronds were then transported to University College Technology Sarawak (UCTS) for subsequent studies. The fronds were then cut longitudinally of thickness 2-4 $\mathrm{mm}$ and later compressed using rollers compressed machine to increase their density before undergoing air-drying.

\section{Drying}

The compressed PFOP were air-dried for 12 hours to reduce moisture in them. The air-drying process is necessary to prevent fungi and insects' attacks. Once the equilibrium moisture content attained $(14 \%$ in Malaysia) the drying process is stopped.

\section{Adhesive}

Two (2) types of adhesive commonly used by the wood composite industry were used in this study to produce the bio-composite PFOP. They were phenolformaldehyde (PF) and urea-formaldehyde (UF) adhesive.

\section{Composite bio-Panels making}

After undergoing the air-drying process, the compressed oil palm fronds were bonded together with $12-15 \%$ of adhesives. $1 \%$ of hardener $\left(\mathrm{NH}_{4} \mathrm{Cl}\right)$ added. The fronds manually compressed using a moulding box $350 \times 350 \mathrm{~mm}$ in size. They later transferred to a single-opening hydraulic hot-pressed machine with a platen temperature of $125 \pm 5^{\circ} \mathrm{C}$ for phenolformaldehyde adhesive and $100 \pm 5^{\circ} \mathrm{C}$ for ureaformaldehyde adhesive. The oil palm fronds biocomposite panels turned into a panel of $20 \mathrm{~mm}$ in thickness. Panels produced from fronds at a different portion from three types of condition groups using two different types of adhesive PF and UF, respectively.

A three-step-down method of pressing of a 40 $\mathrm{sec} / \mathrm{mm}$ for phenol-formaldehyde adhesive, and a 30 $\mathrm{sec} / \mathrm{mm}$ for urea-formaldehyde adhesive. The distances bars $20 \mathrm{~mm}$ in thickness were inserted between the hot platens during hot pressing. All this bio-composite panels were cut into a various size of the test specimens. They were conditioned to attain moisture content of about $12 \pm 1 \%$, at temperature and relative humidity of $20 \pm 3^{\circ} \mathrm{C}$ and $65 \pm 3 \%$ respectively for 72 hours.

\section{Physical studies of bio composite PFOP}

The physical studies tests and evaluation were conducted by the International Organization for Standardization (ISO) standards.

\section{Density}

The density determined by measuring the weight and volume of the testing samples at $12 \%$ moisture content [22]. Each sample tested to an accuracy of $0.01 \mathrm{~g}$ by using an analytical balance. The volumes determined by using a water displacement method. The standard ISO 13061-2017 applied here. The initial weight was taken and then oven-dried at $103 \pm 2^{\circ} \mathrm{C}$ until their moisture content reaches to $12 \%$ moisture content. 


\section{Basic Density}

The basic density determined according to ISO 130612017. The weight at oven-dry and volume at the green stage of each sample recorded - the value of test samples measured to an accuracy of $0.01 \mathrm{~g}$ by using an analytical balance. The water displacement method was used to measure the volumes. The initial weights were taken before the samples underwent oven-drying at $103 \pm 2^{\circ} \mathrm{C}$ to attain constant weights [23]. To prevent the water absorption, the specimens were dipped slightly into the melting wax.

\section{Strength Studies of Composite Bio-Panels}

Testing and evaluation of the strength of the biocomposite PFOP adopted following the ISO 130614:2014, ISO 13061-3:2014, and ISO 13061-17:2017 [24],[25],[26] respectively. Testing included the static bending of modulus of elasticity (MOE), modulus of rupture (MOR), and the compression for modulus of rupture (MOR) using Testometric universal testing machine, M500-50CT, United Kingdom.

\section{Static Bending Strength}

The static bending tests following the ISO 130614:2014 [24] for MOE and ISO 13061-3:2014 [25] for MOR using the Universal Testing Machine. The specimen supported on a span of $280 \mathrm{~mm}$ and the force using a loading head applied at mid-span. The tests were stopped once the samples reach their breaking points. The MOE, MOR and the proportional limit with ultimate load and deflection were recorded and calculated automatically by the computer connected to the testing machine.

\section{Compression Strength}

The compression strength test and evaluation followed the ISO 13061-17:2017 [27] for MOR assessments using a Universal Testing Machine. This test conducted with a constant rate of loading or movement of the loading head of the machine.

\section{RESULTS AND DISCUSSION}

\section{The Physical Studies}

The physical studies investigated in this study included the density and basic density of the bio-panels. These studies are necessary to understand the panels behaviours and performances. These two properties influenced directly on the strength of the panels.

\section{Density}

Density is an excellent indicator of the amount of substance contained in a piece of wood [28]. The density of the bio composite PFOP will depend on the condition groups, portions and types of the adhesive that have been used for bonding this bio-composite lumbers. The density value that had been evaluated on the bio composite PFOP was determined at moisture content equal to $12 \%$.

Figure 1 shows the results of value for density these bio composite PFOP for each condition group, portion, and adhesive type. The panels with the highest density came from the bottom portion for each condition group, followed by the middle and then top portions, respectively. The dried condition group possessed the highest density values for every portion compared to others follow by the felled and green condition groups. The density values decrease from the bottom to top portions for each condition group, meanwhile, the dried condition group possessed the highest density values for every portion compared to others follow by the felled and green condition groups [1].

The density is affected by the anatomical structure in the oil palm fronds influences by the present of the vascular bundles and parenchymatous tissues at various quantity. The ANOVA in Table 1 support this statement. The significant difference existed between density with condition groups and portions. However, no significant difference observed for the adhesives that had been used to produce the bio composite PFOP. These showed that the types of adhesive were not influenced to the density value of the bio-composite lumbers. The density of the bio composite PFOP higher compared to the oil palm fronds density by the effect of adhesive penetration that have been used in producing this bio-composite lumbers. The presence of both adhesives at certain quantity increases the density of the oil palm fronds bio-composite panels. They cause the increase in a material substance per unit volume in these bio-composite PFOP.

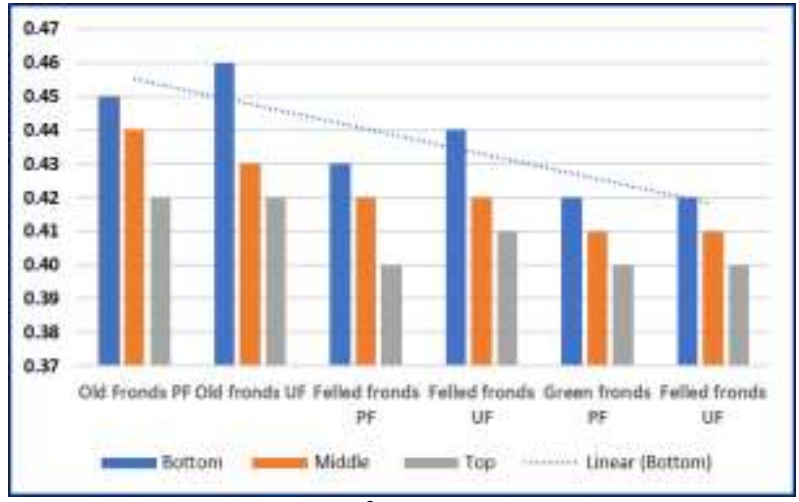

Figure 1: Density $\left(\mathrm{g} / \mathrm{cm}^{3}\right)$ of the bio composite PFOP using PF and UF

\section{Basic Density}

The measuring basic density value for biocomposite PFOP was similar to density value 
evaluation where the difference between calculating density value and basic density value based on weight at moisture content equal to $12 \%$ for density value, and the oven-dry weight for basic density according to Organization for Standardization (ISO) standard (ISO 13061-17:2017) [27]. The basic density for the bio composite PFOP for each condition group, portion and adhesive type were shown in Figure 2. The basic density decreases from the bottom to top portions for each condition group. However, the dried condition groups possessed the highest basic density values for every portion compared to others follow by the felled and green condition groups. Their trend was like the density value, merely different in number value because of its way calculation has been done.

Figure 2 summarized the deceases of bio composite PFOP basic density from the bottom to top portions for each condition group and from the dried to green condition groups for each portion were same situation with the basic density value of the oil palm fronds. The high amount of fibrous vascular bundles, especially at the bottom portion of the oil palm fronds gives influences it them having higher in basic density value compared to other portions [29]. The basic density in wood were differently according to their cell size, cell wall thickness and relative amount of solid cell wall material [30]. Rowell stated that the present in higher amount of mature and thickly cells at the bottom part of wood resulted in higher basic density values compared to than others part. This agrees with basic density values that had been recorded in this study where the bio composite PFOP from the bottom portion got higher in basic density value than other portions. This agrees with an earlier study by Haygreen and Bowyer [31].

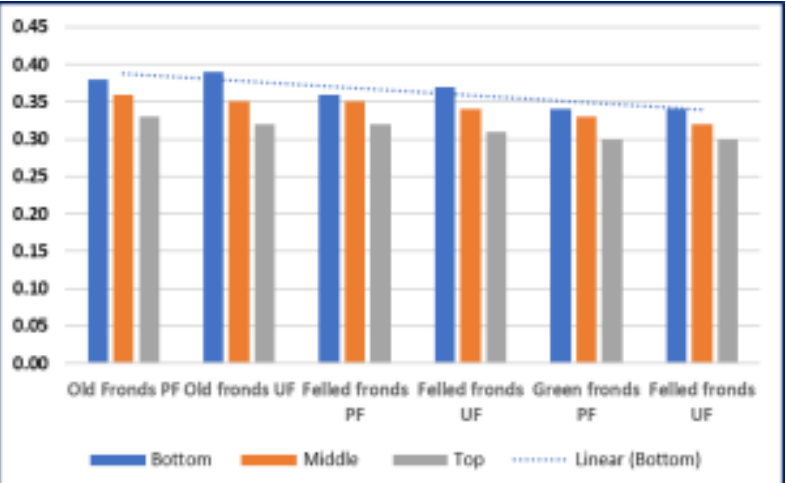

Figure 2: Basic density $\left(\mathrm{g} / \mathrm{cm}^{3}\right)$ of the bio composite PFOP using PF and UF

The ANOVA Table 1 showed significant difference exist between the basic density with condition and portions groups. No significant difference, however noted for the adhesive types used in the studies. This showed the types of adhesive used does not influenced to the basic density value of the bio composite PFOP. However, the basic density of oil palm fronds bio-composite PFOP higher compared to the oil palm fronds basic density by the effect of adhesive that have been used in producing this biocomposite PFOP. The increasing of bio-composite PFOP basic density probably related to adhesive penetration into the bio composite PFOP. The parenchyma behaves like a sponge and can easily absorb moisture [32],[33]. Thus, the bio-composite PFOP could easily absorb phenol and urea formaldehyde adhesive during the manufacturing process and leads to the increase in the basic density of the bio composite PFOP. It was assumed that the adhesive penetrations possessed higher density as well as basic density and enhanced the strength of the bio composite PFOP.

\section{Strength Studies}

The strength of wood is measured by its resistance to the exterior forces that tend to deform it [34]. This resistance, however, is dependent on their magnitude and the manner of loading forces applied (bending, compression, shear, tension, etc.). Due to the strength characteristics, wood exhibits different strength properties in different growth directions; therefore, it is mechanically anisotropic [32],[35]. The strength properties are the most important characteristics of wood product to be used in structural applications [36]. In any structural application, the wood which possesses higher strength is preferably selected. The floor joint and rafters, wall sheathing, and sub-flooring uses these structural wood products [34].

Testing on the strength properties conducted including static bending strength (MOE and MOR) and compression strength (MOR) [23]. The testing was carried out based on the International Organization for Standardization (ISO) standard for the strength properties evaluation. The analysis of the strength properties of the bio-composite PFOP particularly investigated the effect of condition groups, portions, and types of adhesive. The adhesives that have been used in producing the bio-composite PFOP were phenol and urea-formaldehyde.

\section{Static Bending Strength}

In the static bending strength tests bending stress is applied to the bio-composite PFOP to determine their stiffness or MOE, as well as the amount of forces required to cause it to fail. The bending strength of wood is expressed in MOR [34]. These are the most important parameters which usually are used for engineering purposes.

In the static bending of the oil palm fronds biocomposite PFOP, testing was conducted and data obtained analyzed to examine the effect of condition 
groups (dried, felled and green), portions (bottom, middle and top) and adhesives (phenol and ureaformaldehyde) to obtained the MOE and MOR. The summarized result of static bending test is presented in Tables 3 and 4. The bottom portion possessed the highest value for both MOE and MOR strength in static bending for every condition group. The dried condition group contained the highest value for each portion compared to the felled and green condition groups.

The values of the oil palm fronds bio-composite PFOP (both from phenol and urea-formaldehyde adhesive) for MOE and MOR in static bending decreases from the bottom to top portions for every condition group and from the dried to green condition groups, respectively. Figure 3 shows the MOE strength in the dried condition group from the bottom, middle and top portions for phenol-formaldehyde bio composite PFOP at 999.61, 952.29 and $844.18 \mathrm{~N} / \mathrm{mm}^{2}$. The MOE for urea-formaldehyde bio-composite panels were at $980.31,949.40$ and $840.40 \mathrm{~N} / \mathrm{mm}^{2}$ from the bottom, middle and top portions for dried condition group, respectively. The MOE strength decreases from the bottom to top portion for dried condition group both of phenol either urea-formaldehyde bio composite PFOP. The same observations were noted for the other two condition groups, which were the felled and green condition.

The strength for the MOE at the bottom portion from the dried, felled, and green groups condition of phenol-formaldehyde bio-composite panels were at 999.61, 979.15 and $935.36 \mathrm{~N} / \mathrm{mm}^{2}$, respectively. The value of strength MOE at the bottom portion of ureaformaldehyde bio composite PFOP from the dried, felled, and green condition were at 980.31, 953.93 and $936.24 \mathrm{~N} / \mathrm{mm}^{2}$. The MOE decreases from the dried to green groups condition for the bottom portion either for phenol or urea-formaldehyde bio composite PFOP at the middle and top portions too according to from the dried, felled, and green group condition.

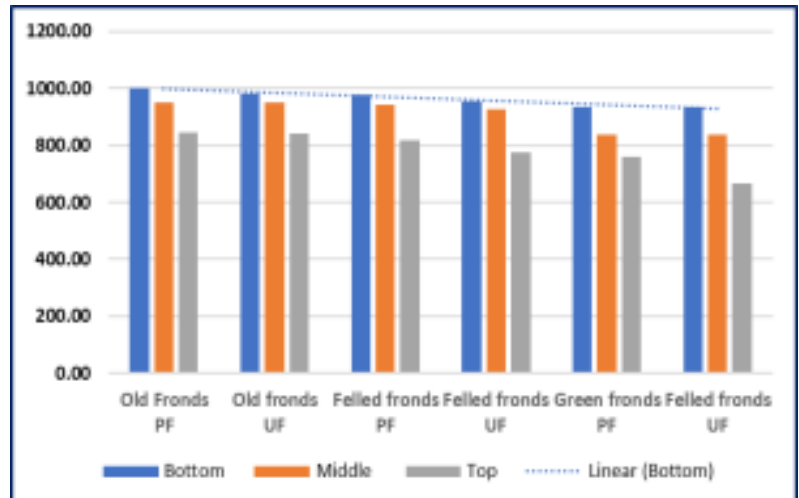

Figure 3: The MOE $\left(\mathrm{N} / \mathrm{mm}^{2}\right)$ in static bending of bio composite PFOP using PF and UF
Figure 4 summarized the test result of the biocomposite PFOP at the different group condition, portions, and adhesive types. The MOR of the oil palm fronds bio-composite panels was gradually decreasing from the bottom to top portions for each condition group and from dried to green condition groups for every portion. This include for both two types of the adhesive that have been used in producing the $b$ bio composite PFOP which were phenol and ureaformaldehyde adhesive. The MOR strength for the dried condition group from the bottom portions at 16.66, middle at 12.55 and top at $11.72 \mathrm{~N} / \mathrm{mm}^{2}$ respectively for phenol-formaldehyde adhesive oil palm frond bio-composite PFOP. The MOR for ureaformaldehyde bio composite PFOP were at 15.40, 12.38 and $11.63 \mathrm{~N} / \mathrm{mm}^{2}$, respectively. This similar trend also observed to the felled and green groups condition from the bottom towards top portions.

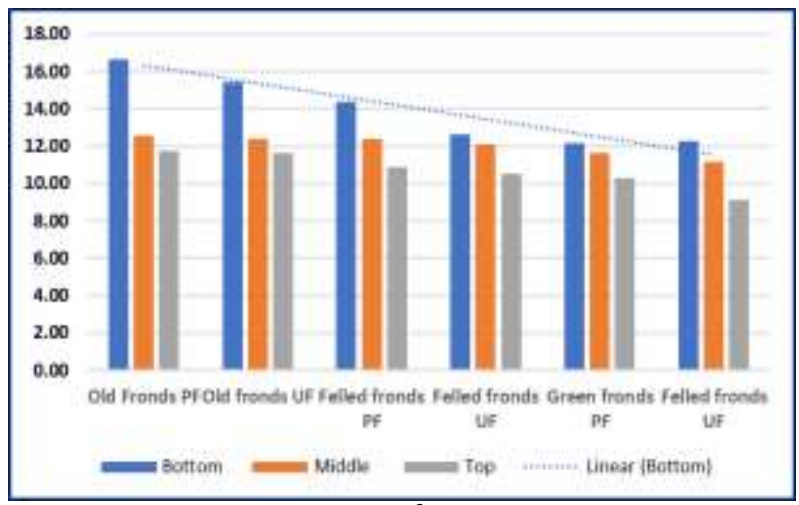

Figure 4: The MOR $\left(\mathrm{N} / \mathrm{mm}^{2}\right)$ in static bending of bio composite PFOP using PF and UF

To investigate the effect of groups condition of the oil palm fronds in producing this bio-composite PFOP in the MOR static bending strength, an analysis was carried out examining the distribution of MOR shown in Figure 4. The results showed that for the bottom portion for each group condition (dried, felled, and green) from phenol-formaldehyde bio composite PFOP, the MOR was 16.66, 14.38 and $12.16 \mathrm{~N} / \mathrm{mm}^{2}$ respectively. The MOR for urea-formaldehyde biocomposite panels were $15.40,12.62$ and $12.25 \mathrm{~N} / \mathrm{mm}^{2}$. The strength respectively decreased from the dried towards groups condition for bottom portion either both of adhesive types that have been used in this biocomposite PFOP. The MOR decreases too in the other two portions (middle and top portions). These similar observations to the MOE value influence by the bottom to the top portions where the MOR values decrease for each condition group as well as from old towards green groups condition.

Both the MOE and MOR values for the biocomposite PFOP decreases from the bottom, middle, and top portions, and towards the groups' condition 
from dried, felled, and green condition groups. These also occurred in both bio-composite panels made from phenol and urea-formaldehyde adhesive. The variations in the MOE and MOR values along the tree height can be explained by the decrease in condition of wood and fibre length from bottom to the top of the tree [37]. This is due to the reductions of vascular bundles from the bottom to top portions as well as from the dried to green groups condition. The presence of vascular bundle influences the quantity of fibre cell present. This directly increases the density and basic density of the panels. High values in density and basic density gives rise to the strength properties of wood [31],[38]. This explains why the bottom portions possess higher value for both MOE and MOR strengths in comparison to the middle and top portions for each group condition as well as dried group condition than felled and green groups condition.

The strength properties of the panels have a significant correlation with density and basic density [39]. The MOE and MOR strength of the bio-composite PFOP from the bottom portion possess higher values than middle and top portions for each group condition as well as towards dried, felled and green groups condition for every portion. The ANOVA in Table 1 shows the significant difference between MOE and MOR of static bending with condition groups and portions.

The result showed that the bio-composite PFOP phenol-formaldehyde adhesive possesses high value for both the MOE and MOR than urea-formaldehyde adhesive. This is due to the urea-formaldehyde adhesive has a high amount of solid content compared to the phenol-formaldehyde adhesive. The distribution of phenol-formaldehyde adhesive located irregularly in the structures of the bio-composite PFOP [28]. When the stress applied, the stress could not be transferred consistently between the fibre and the surrounding tissues. The penetration of high viscosity of ureaformaldehyde adhesive probably breaks the cell wall of the composite bio-panels [28]. This action would make the fibre and the surrounding tissues unable to withstand greater loads. However, no significant difference observed in the results of MOE and MOR in static bending according to the ANOVA in Table 1 in adhesive type. Proved, the types of adhesive were not too much influenced by the density value of the biocomposite PFOP.

\section{Compression Strength}

In this subtopic, the study was conducted to investigate the compression strength of oil palm fronds biocomposite PFOP. The experiment runs in using the Universal Testing Machine. Compression strength defined as the maximum stress sustained by the compression of a specimen [40]. The compression strength of composite panels was strongly dependent on the effectiveness of the matrix in supporting the fibre against buckling [41]. It was noted that the characteristic of the compression load-deformation curve was like those for static bending strength [42],[43].

Testing on this strength property was conducted by the ISO 13061-17:2017 [26]. The obtained data was examined using statistical analysis to define the effect of three parameters which are on condition groups (Dried, felled, and green), portions (bottom, middle and top), and also types of adhesive (phenol and ureaformaldehyde) to the compression strength of the oil palm fronds bio-composite PFOP.

Table 5 showed the compression strength of dried group condition from bottom to top portions were at 473.17, 395.93 and $260.22 \mathrm{~N} / \mathrm{mm}^{2}$ for phenolformaldehyde bio composite PFOP, while for the ureaformaldehyde composite bio-panels OPF, the result was at $459.52,344.60$ and $260.00 \mathrm{~N} / \mathrm{mm}^{2}$ respectively. The compression strength decreases from the bottom towards to middle and top portions for dried group condition. Similar decrement distribution observed to the felled and green groups condition towards from bottom, middle and top portions.

To investigate the effect of condition groups to compression strength of oil bio composite PFOP, the data in Table 5 showed that the trend for each portion towards dried, felled and green condition groups were similar to portion factor from bottom to top portions. The result of bottom portion according from dried, felled, and green condition groups were 473.17, 453.67 and $301.49 \mathrm{~N} / \mathrm{mm}^{2}$ for phenol-formaldehyde bio composite PFOP at 459.52, 431.88 and $312.94 \mathrm{~N} / \mathrm{mm}^{2}$ respectively for urea-formaldehyde bio composite PFOP. It is clearly showing the decrement towards dried, felled, and green groups condition for the bottom portion and this occurred to the middle and top portions. The decrement trend of MOR in compression show similar in a trend of the MOE and MOR in the static bending. The vascular bundles' quantity and distributions along the oil palm fronds could be attributed to these properties. The differences in the density and basic density values influenced the distribution result of compression strength for the groups' condition and portions. The bottom portions have higher values in compression than the middle, and top portions for each group condition for the dried group condition follow by felled and green condition for every portion. The results are shown in the ANOVA in Table 1, where a significant difference observed between compression strength with condition groups and portions. The decreases in density and strength properties along the length of the fronds from the bottom to the top portions from old to green condition groups [44]. Some strength properties of the panels 
showed failure in the compression, especially lowdensity panels [45],[46].

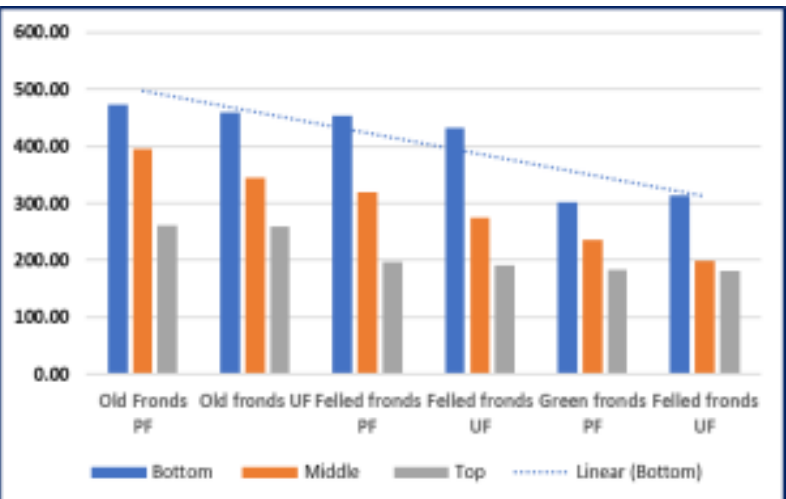

Figure 5: The MOR $\left(\mathrm{N} / \mathrm{mm}^{2}\right)$ in the bio composite PFOP using PF and UF

The result showed that the values for each phenolformaldehyde bio-composite panels possessed higher impact in compression than the urea-formaldehyde bio composite PFOP. The higher compression strength of oil palm fronds bio-composite PFOP with phenolformaldehyde adhesive as compared to ureaformaldehyde bio composite PFOP could be due to the presence of phenol-formaldehyde adhesive. Properly cured panels are often tougher than the wood itself [42],[47]. The effectiveness of the phenol and ureaformaldehyde adhesive in enhancing the compression properties showed a similar trend as in the static bending strength. The phenol-formaldehyde bio composite PFOP have a higher value in compression strength compared to urea-formaldehyde composite bio-panels. However, the differences are not very significant, as shown in the ANOVA in Table 1.

\section{A. ANOVA on Physical and Strength Studies}

The ANOVA in Table 1 shows both the physical and strength properties of the bio-composite PFOP. The ANOVA determined whether there exist or not. The methods used to check either the significant difference between physical properties (density and basic density) and strength properties (MOE for static bending strength and MOR for static bending including compression strength) with condition groups, portions and types of adhesive of the bio-composite PFOP. Significant differences existed between the physical properties (density and basic density) and the strength properties (static bending strength (MOE and MOR) as well as the compression strength (MOR)) within the groups' condition and portions factors. The significant differences were at $\mathrm{P}$-value $\leq 0.01$. The analyses indicated that groups condition and portions affecting and gives influenced to the results on physical and strength properties of the bio-composite PFOP. There is no significant difference, however, existed between physical (density and basic density) and strength (static bending strength (MOE and MOR) and compression strengths (MOR) on the types of adhesive factors. The uses of either adhesive do not affect the quality of the panels produced.

Table 1: ANOVA on physical and strength properties of the bio composite PFOP

\begin{tabular}{lllrrl}
\hline Source of Variance & Dependent Variable & DF & Sum of Square & Mean Square & F-Ratio \\
\hline Dried Fronds & Density & 2 & 0.0108 & 0.0054 & $7.94^{* *}$ \\
Felled Fronds & Basic Density & 2 & 0.0180 & 0.0197 & $28.75^{* *}$ \\
Green Fronds & MOEb & 2 & 155675.0000 & 77837.5000 & $57.05^{* *}$ \\
& MORb & 2 & 79.0218 & 39.5109 & $40.39^{* *}$ \\
& MORc & 2 & 255794.0000 & 127897.0000 & $63.81^{* *}$ \\
\hline Dried Fronds & Density & 2 & 0.0112 & 0.0056 & $8.26^{* *}$ \\
Felled Fronds & Basic Density & 2 & 0.0394 & 0.0090 & $28.75^{* *}$ \\
Green Fronds & MOEb & 2 & 507856.0000 & 253928.0000 & $80.62^{* *}$ \\
& MORb & 2 & 157.7170 & 78.8586 & $140.95^{* *}$ \\
& MORc & 2 & 565023.0000 & 287897.0000 & $0.20 \mathrm{~ns}$ \\
\hline Dried Fronds & Density & 2 & 0.0001 & 0.0001 & $0.20 \mathrm{~ns}$ \\
Felled Fronds & Basic Density & 2 & 0.0004 & 0.0004 & $1.28 \mathrm{~ns}$ \\
Green Fronds & MOEb & 2 & 11232.8000 & 11232.8000 & $8.23 \mathrm{~ns}$ \\
& MORb & 2 & 8.2313 & 8.2313 & $8.41 \mathrm{~ns}$ \\
& MORc & 2 & 7538.0100 & 7538.0100 & $3.76 \mathrm{~ns}$ \\
\hline
\end{tabular}


Correlation Coefficient between Physical and Strength Bio Composite PFOP

Table 2 manifests the correlation between physical and strength properties of the bio-composite PFOP. A correlation existed between density and basic density of bio-composite PFOP within the groups' condition and portions. Negative correlations observed between density and condition groups $(\mathrm{r}=-0.3657)$ and portions $(\mathrm{r}=-0.3748)$. The basic density of the bio-composite PFOP $(r=0.4435, \quad r=-0.6588)$ was negatively correlated with condition groups and portions.

From dried to green condition groups for each portion and towards the bottom, middle and top portions for every condition group, there were decreasing in density as well as basic density values. Table 1 highlighted the ANOVA statistical analysis. The correlation coefficient was noted between density and the basic density $(\mathrm{r}=0.5611)$. A positive correlation existed between them, and there was a significant difference at $\mathrm{P}$-value $\leq 0.01$. A positive correlation relationship exists between adhesive types with density value $(r=0.0411)$, and negative correlation noted between the adhesive types and the basic density value $(r=-0.0668)$. This correlation relationship, however, was not significant between (see ANOVA in Table 1). Indicated that types of an adhesive factor were not affected the density as well as basic density value of the oil palm fronds bio-composite PFOP since the correlation coefficient was too small.

The correlation analysis between the strength properties (MOE for static bending strength and MOR for static bending, including compression strength) with other bio-composite PFOP properties are presented in Table 2. There was a correlation between condition groups factor with the strength properties values. The negative correlation obtained between groups condition with the MOE of the static bending strength $(r=-$ $0.4321)$, the MOR of static bending strength $(r=-$ $0.4927)$ and MOR for compression strength $(r=-$ $0.5029)$. A similar trend on the correlation obtained between portions in the MOE of the static bending strength $(\mathrm{r}=-0.7862)$, the MOR of static bending $(\mathrm{r}=$ $0.6939)$ and finally MOR for compression $(r=0.7481)$.

The negative correlation show between groups' condition and portions with strength (MOE and MOR for static bending strength and MOR for compression strength). The strength of bio-composite PFOP decreases towards the bottom, middle and top portions for each condition group as well as from Dried to green groups condition for the frond portions. The ANOVA in Table 1 shows the significant difference at $\mathrm{P}$-value $\leq 0.01$.

The strength properties of woody material have a close and significant correlation with density and the basic density [39]. The increases in density and basic density directly increase the strength properties of the materials, which including the static bending and compression-demonstrated in Table 2 of the correlation analysis. A positive correlation existed between the density, the basic density, the strength properties in the MOE and MOR in static bending and MOR in compression of bio-composite PFOP towards groups condition (dried to green groups condition) and the frond portions (bottom to top portions). The positive correlation obtained between the density and the MOE of static bending $(r=0.3750)$, the MOR in static bending strength $(r=0.4045)$ and the MOR in compression strength $(r=0.5339)$. Correlation between the basic density with these three (3) strengths resulted in the $r=0.7241$ and $r=0.6669$ in MOE, and the MOR in static bending strength and $r=0.7356$ in the MOR of the compression. All correlations occurred at significant differences of P-value $\leq 0.01$ (see ANOVA in Table 2). The effect of adhesive types on the strength of the biocomposite PFOP produced a negative correlation between of them at $r=-0.1196$ and $r=0.1592$ of the MOE and MOR in the static bending strength and the MOR of compression strength at $r=-0.0867$. A similar trend occurred in the correlation relationship between physical properties (density and basic density) of oil palm fronds bio-composite panels with types of adhesive used. The correlation relationship produced no significant between them shown in the ANOVA of Table 2. The types of adhesive do not affect the strength properties of the bio-composite panels. The positive correlation observed between these three strengths, where the $r=0.7673$ and $r=0.7870$ between the MOE in the static bending strength and the MOR in static bending and compression strength. The $\mathrm{r}=$ 0.7889 occurred between the MOR of static bending and the MOR of compression at $\mathrm{P}$-value $\leq 0.01$. 
Characterization of Oil Palm Fronds Panel at Different Conditions and Positions with Formaldehyde Adhesive

Table 2: Correlation analysis between physical and strength properties of bio composite PFOP

\begin{tabular}{lcccccccc}
\hline & Condition & Portion & Adhesive & Density & Basic Density & MOEb & MORb & MORc \\
\hline Condition & 1.0000 & $0.0000 \mathrm{~ns}$ & $0.0000 \mathrm{~ns}$ & $-0.3657^{* *}$ & $-0.4435^{* *}$ & $-0.4321^{* *}$ & $-0.4927^{* *}$ & $-0.5029^{* *}$ \\
Portion & & 1.0000 & $0.0000 \mathrm{~ns}$ & $-0.3748^{* *}$ & $-0.6588^{* *}$ & $-0.7862^{* *}$ & $-0.6939^{* *}$ & $-0.7481^{* *}$ \\
Adhesive & & & 1.0000 & $0.0411 \mathrm{~ns}$ & $-0.0668 \mathrm{~ns}$ & $-0.1196 \mathrm{~ns}$ & $-0.1592 \mathrm{~ns}$ & $-0.0867 \mathrm{~ns}$ \\
Density & & & & 1.0000 & $0.5611^{* *}$ & $0.3750^{* *}$ & $0.4045^{* *}$ & $0.5339^{* *}$ \\
Basic Density & & & & & 1.0000 & $0.7241^{* *}$ & $0.6669^{* *}$ & $0.7356^{* *}$ \\
MOEb & & & & & & 1.0000 & $0.7673^{* *}$ & $0.7870^{* *}$ \\
MORb & & & & & & & 1.0000 & $0.7889^{* *}$ \\
MORc & & & & & & & & 1.0000 \\
\hline
\end{tabular}

Acronym: $* *=$ significant at $99 \%, \mathrm{~ns}=$ not significant, $\mathrm{MOEb}=$ modulus of elasticity for static bending strength,

$\mathrm{MOR} b=$ modulus of rupture for static bending strength, $\mathrm{MOR} c=$ modulus of rupture for compression strength

\section{CONCLUSION}

High in density and basic density bio composite PFOP produced from dried oil palm fronds, followed by felled and green fronds. Similar properties are obtained from the bottom, middle and top portions of the fronds. The phenol-formaldehyde bio composite PFOP possessed an overall higher in MOE, MOR for both the static bending and compression strengths. The phenolformaldehyde bio-composite panels can reach the maximum value of MOE at $999.61 \mathrm{~N} / \mathrm{mm}^{2}$ made from the bottom portion of dried group condition. The ureaformaldehyde bio-composite panels from the top portion of the green condition group possessed lower value at $666.30 \mathrm{~N} / \mathrm{mm}^{2}$. Similar trends occurred the panels made from the dried, felled, and green groups condition for every fronds portion. The phenolformaldehyde adhesive of the dried group condition from the bottom, middle and top portions were at 16.66, 12.55 and $11.72 \mathrm{~N} / \mathrm{mm}^{2}$ respectively in MOR. The MOR in compression strength of the panels decreases along the bottom to top portions for each group condition at every portion both of phenol and ureaformaldehyde bio composite PFOP.

\section{ACKNOWLEDGMENT}

This study financed University College of Technology Sarawak Grant (UCTS/RESEARCH/2/2018/01) and UCTS/RESEARCH/2/2018/04). The authors expressed their gratitude to University College of Technology Sarawak (UCTS) for permission on using their laboratory and timber workshops in the preparation and analysis parts of the study.

\section{REFERENCES}

[1] Wahab, R., Sulaiman, M.S., Mokhtar, N., Ghani, R.S.M., Samsi, H.W., Yusof, M. 2018. Properties of hibiscus cannabinus and elaeis guineesis frond fibers eco-composite boards. International Journal of Current Research. 10, (05), 6977069775.

[2] Wahid, M. B., Abdullah, S. N. A. and Henson, I. E. 2004. Oil palm: Achievements and potential in new directions for a diverse planet. Proceedings of the $4^{\text {th }}$ International Crop Science Congress, September 26 - October 1, 2004. Brisbane, Australia.

[3] Dugani, R, Khalil H.P.S, Nurjana A., Sumardi I, Aditiawati P., Darwis A., Sulaeman A., Rosamah E. and Riza M. 2017. Bionanomaterial from agricultural waste and its application.

[4] Wahab, R., M.S.M. Rasat, Hashim W. Samsi, M.T. Mustafa \& S.M.M. Don. 2017. Assessing the suitability of Agro-Waste from Oil Palm Empty Fruit Bunches as Quality Eco-Composite Boards. Journal of Agricultural Science 9 (8): 237-247. ISSN 1916-9752 E-ISSN 1916-9760. Doi: 10.5539/jas. v9n6p251. Published by Canadian Center of Science and Education.

[5] Uysal, B. 2005. Bonding strength and dimensional stability of laminated veneer lumbers manufactured by using different adhesives. Journal of Adhesion and Adhesives. 25: 395-403.

[6] Sulaiman, M.S., Ramle, S.F.M., Geng, B.J., Hashim, R., Sulaiman, O., Ibrahim, N.I., Zaudin, N.A.C. 2016. Bambusa vulgaris: Chemical composition and cell wall structure. European International Journal of Science and Technology, 5 (9): 27-39.

[7] Zulkifli, R., Mohd Nor, M. J., Mat Tahir, M. F. Ismail, A. R. and Nuawi, M. Z. 2008. Acoustic properties of multi-layer coir fibres sound absorption panel. Journal of Applied Sciences. 8 (20): 37093714.

[8] Hill, C. A. S., Abdul Khalil, H. P. S. and Hale, M. D. 1998. A study of the potential of acetylation to 
improve the properties of plan fiber. Journal of Industrial Crops and Products. 8: 53.

[9] Mohamad, H., Anis, M. and Wan Hasamudin, W. H. 2003. Energizing the wood-based industry in Malaysia. Proceedings of the $6^{\text {th }}$ National Seminar on The Utilization of Oil Palm Tree, December 15-17, 2003, Oil Palm Tree Utilisation Committee (OPTUC), Kuala Lumpur, Malaysia. 6-13.

[10] Mohamad, H., Ridzuan, R., Anis, M., Wan Hasamudin, W. H., Kamaruddin, H., Ropandi, M. and Astimar, A. A. 2002. Research and development of oil palm biomass utilization in wood-based industries. Journal of Palm Oil Developments. 36: 1-5.

[11] Tanaka, R., Peng, L. C. and Wan Rosli, W. D. 2002. Preparation of cellulose pulp from oil palm empty fruit bunches (EFB) by processes including pre-hydrolysis and ozone bleaching. Proceedings of the USM-JIRCAS Joint International Symposium-LignocelluloseMaterial of the Millenium: Technology and Application, March 2021, 2001, Penang, Malaysia. 33-8.

[12] Ridzuan, R., Stephen, S. and Mohd Ariff J. 2002. Properties of medium density fibreboard from oil palm empty fruit bunch fibre. Journal of Oil Palm Research. 14 (2): 34-40.

[13] Laemsak, N. and Okuma, M. 2000. Development of boards made from oil palm frond II: Properties of binderless boards from steamexploded fibres of oil palm. Journal of Wood Science. 46 (4): 322326.

[14] Chew, T. L. 1987. Particleboard manufactured from oil pal stems: A pilot scale study. FRIM Occasional Paper No. 4. Kepong: Forest Research Institute Malaysia (FRIM). 8.

[15] Kochummen, A. M., Wong, W. C. and Killmann, W. 1990. Manufacture of cement board using oil palm stems. Unpublished IDRC Final Report.

[16] Abraham, J. M., Zakaria, M. A., Mohd Nor M. Y. and Simatupang, M. H. 1998. Suitability of kraft pulp from oil palm trunk for cellulose fibre reinforced cement boards. Journal of Tropical Forest Product. 4 (2): 65-159.

[17] Schwarz, H. G. 1985. Cement-bonded boards in Malaysia. Proceedings of the fibre and particleboards bonded with inorganic binders, Forest Research Soc, USA. 91-93.

[18] Liew, K. C., Jalaluddin, H., Paridah, M. T., Khairul Zaman, M. D. and Mohd Nor, M. Y. 2000. Properties of oil palm frondpolypropylene composite. Proceedings of the Utilization of Oil Palm Tree-Oil Palm Biomass: Opportunities and Challenges in Commercial Exploitation. 8-116.

[19] Othman, S., Rokiah, H., Wahab, R., Hashim, W. S. and Azmy, M. 2008. Evaluation on some finishing properties of oil palm plywood. Journal of Holz Roh Werkst. 66: 5-10.

[20] Ho, K. S., Choo, K. T. and Hong, L. T. 1985. Processing, seasoning and protection of oil palm lumber. Proceedings of the National Symposium on Oil Palm by-products for Agrobased Industries, November 5-6, 1985, Kuala Lumpur, Malaysia. 43-51.

[21] Wahab, R., Hashim, W. S., Aminuddin, M., Othman, S. and Rafidah, S. 2008. Properties of laminated veneer lumbers from oil palm trunks. Journal of Plant Sciences. 3 (4): 255-259.

[22] Sulaiman, M.S., Ramle, S.F.M., Hashim, R., Sulaimam, O., Amini, M.H.M., Geng, B.J. 2018. The classical mechanics engineered of Bambusa vulgaris and Schizostachyum brachycladum. Journal of Tropical Resources and Sustainable Science 6 (2018): 57-61.

[23] Ghani, R.S.M., Wahab, R., Musthafa, N.M.C., Mokhtar, N., Sulaiman, M.S., Lee, M.D. 2018. Physical and Mechanical Properties of CassavaBamboo Composite Lumber. Journal of Engineering and Science Research 2 (6): 06-09.

[24] ISO 13061-4:2014. Physical and mechanical properties of wood - Test methods for small clear wood specimens - Part 4: Determination of modulus of elasticity in static bending.

[25] ISO 13061-3:2014. Physical and mechanical properties of wood - Test methods for small clear wood specimens - Part 3: Determination of ultimate strength in static bending.

[26] ISO 13061-17:2017. Physical and mechanical properties of wood - Test methods for small clear wood specimens - Part 17: Determination of ultimate stress in compression parallel to grain.

[27] ISO 13061-17:2017. Physical and mechanical properties of wood - Test methods for small clear wood specimens - Part 17: Determination of ultimate stress in compression parallel to grain.

[28] Abdullah, C. K. 2010. Impregnation of Oil Palm Trunk Lumber (OPTL) using Thermoset Adhesives for Structural Applications. Master Thesis. Universiti Sains Malaysia.

[29] Mohamad, H., Zin, Z. Z. and Abdul Halim, H. 1985. Potentials of oil palm by products as raw materials for agro-based industries. Proceedings of National Symposium on Oil Palm by-product for Agro-based Industries, Kuala Lumpur, Malaysia.

[30] Rowell, R. M. 1994. The Chemical of Solid Wood. DOI: 10.1021/ba-1984-0207. ACS Publications. Subtitled by Suhaimi Muhammed and Halimathon $\mathrm{Hj}$ Mansor. Kuala Lumpur: Dewan Bahasa dan Pustaka.

[31] Haygreen, J. G. and Bowyer, J. L. 1930. Introduction to Forest Product and Wood Science. 
Characterization of Oil Palm Fronds Panel at Different Conditions and Positions with Formaldehyde Adhesive

Subtitled by Suhaimi Muhammed and Sheikh Abdul Karim Yamani Zakaria. Kuala Lumpur: Ampang Press Sdn. Bhd.

[32] Wahab, R., M.T. Mustafa, Hashim W. Samsi, M. Mohamed, M.S.M. Rasat and Madihan Yusof. 2016. Physical, Mechanical and Morphological Studies on Bio-composite Mixture of Oil Palm Frond and Kenaf Bast Fibers. Journal of Plant Sciences 11 (1-3): 22-30. ISSN: 1816-4951, Academic Journals Inc. USA. DOI: 10.3923/jps.2016.22.30.

[33] Paridah, M. T. and Anis, M. 2008. Process optimization in the manufacturing of plywood from oil palm trunk. Proceedings of $7^{\text {th }}$ National Seminar on the Utilization of Oil Palm Tree, Oil Palm Tree Utilization Committee, Kuala Lumpur, Malaysia. 12-24.

[34] Erwinsyah. 2008. Improvement of Oil Palm Wood Properties Using Bioadhesive. $\mathrm{PhD}$ Thesis. Technische Universität Dresden.

[35] Tsoumis, G. 1991. Science and Technology of Wood - Structure, Properties and Utilization. New York: Van Nostrand Reinhold.

[36] Bowyer, J. L., Shmulsky, R. and Haygreen, J. G. 2004. Forest Product and Wood Sciences - An Introduction (4 ${ }^{\text {th }}$ Edition). Blackwell Publishing Company.

[37] Rulliarty, S. and America, W. A.1995. Natural Variation in Wood Quality Indicators of Indonesian Big Leaf Mahogany (Swietenia macrophylla. King). Proceedings of XX IUFRO World Congress, Tampere.

[38] Mokhtar, N., Wahab, R., Sulaiman, M.S., Ghani, R.S.M., Edin, T. 2020. Rhizophora apiculata: Comparative Properties Between Solid and Engineered Laminated Boards. Borneo Journal of Sciences and Technology, 2 (1): 41-47.

[39] Desch, H. E. 1968. Timber, Its Structure, properties, and utilization. New York: London and Basingstoke Associated companies. CelluloseReinforced Nanofibre Composites. DOI:http:// dx.doi.org/ 10.1016/B978-0-08-100957-4.000036.

[40] Thanate, R., Tanong, C. and Sittipon, K. 2006. An investigation on the mechanical properties of trunks of palm oil trees for the furniture industry. Journal of Oil Palm Research. 114-121.

[41] John, R. L. and Reid, R. J. 1969. Compressive Strength of Boron Composites. Journal of Composite Materials. 3: 48-8.

[42] Wahab, R., Mat Rasat, M.S., Salam, M.A., Moktar, J., Mohamed, M., \& Siti Marlia Mohd Don. 2015. Measurement on Properties of Empty Fruit Bunch Oil Palm Composite Boards at Different Density and Resin Contents. Advance in Environmental Biology 9(23): 352-360. AENSI Journals. ISSN-1995-0756.

[43] Ronald, W. W. and Gjinoli, A. 1997. The Use of Recycled Wood and Paper in Building Applications. Proceedings of Forest Product Society No. 7286. 84-91.

[44] Oyagade, A. O. and Fasulu, S.A. 2005. Physical and Mechanical Properties of Trilepisium madagascariense and Funtumia elastica Wood. Journal of Tropical Forest Science.17(2): 258264.

[45] Khalid, I., Sulaiman, O., Hashim, R., Wahab, R., Jumhuri, N., \& Mat Rasat, M.S. 2015. Evaluation on Layering Effects and Adhesive Rates of Laminated Compressed Composite Panels made from Oil Palm (Elaeis guineesis). Journal of Materials and Design. 68: 24-28. DOI:10.1016 / j.matdes. 2014.12.007, Elsevier Science Direct UK.

[46] Nordahlia, A. S. 2008. Wood Quality of 10-YearOld Sentang (Azadirachta excelsa) Grown from Seedlings and Rooted Cuttings. Master Thesis. University Putra Malaysia.

[47] Baldwin, R. F. 1995. Adhesives and Bonding Techniques. In: Plywood and Veneer-based Products Manufacturing Practuces. California: Miller Freeman Inc. 